\title{
Pharyngeal Airway Dimensions and Head Posture in Obstructive Sleep Apnea Patients with and without Morphological Deviations in the Upper Cervical Spine
}

\author{
Liselotte Sonnesen $^{1}$, Arne Petersson ${ }^{2}$, Søren Berg ${ }^{3}$, Palle Svanholt ${ }^{1}$ \\ ${ }^{1}$ Section of Orthodontics, Department of Odontology, Faculty of Health and Medical Sciences, University of Copenhagen, \\ Denmark. \\ ${ }^{2}$ Department of Oral and Maxillofacial Radiology, Malmö University, Malmö, Sweden. \\ ${ }^{3}$ Clinic for Infant and Adult Sleep Medicine, Lovisenberg Diakonale Sykehus, Oslo, Norway.
}

\author{
Corresponding Author: \\ Liselotte Sonnesen \\ Section of Orthodontics, Department of Odontology \\ Faculty of Health and Medical Sciences, University of Copenhagen \\ 20 Nørre Alle, DK-2200, Copenhagen \\ Denmark \\ Phone: 004535326670 \\ E-mail: alson@sund.ku.dk
}

\begin{abstract}
Objectives: The aim of the study was to analyse differences in pharyngeal airway dimensions and head posture between obstructive sleep apnea patients with and without morphological deviations in the upper cervical spine and to analyse associations between pharyngeal airway dimensions and head posture in the total sample.

Material and Methods: The sample comprised 53 obstructive sleep apnea (OSA) patients of which 32.1\% had upper spine morphological deviations. Accordingly two groups were defined: 17 OSA patients with morphological deviations in the upper spine and 36 without upper spine deviations. Pharyngeal airway dimensions in terms of distances, cross-sectional areas and volume and upper spine morphological deviations were evaluated on cone-beam computed tomography. Head posture was evaluated on two-dimensional generated lateral cephalograms. Differences were analysed and adjusted for age and gender by multiple linear regression analysis.

Results: OSA patients with upper spine morphological deviations had a significantly more backward and curved neck posture (OPT/HOR, $\mathrm{P}<0.01$; OPT/CVT, P < 0.05) compared to OSA patients without spine deviations. No significant differences were found in airway dimensions between patients with and without upper spine deviations. In the total group significant associations were found between head posture and pharyngeal airway distances and cross-sectional area at the nasal floor, epiglottis and hyoid bone level $(\mathrm{P}<0.05, \mathrm{P}<0.01, \mathrm{P}<0.001)$. No significant association was found between head posture and airway volume.

Conclusions: The results may contribute to differentiate obstructive sleep apnea patients and thereby may prove valuable in diagnosis and treatment planning of obstructive sleep apnea patients.
\end{abstract}

Keywords: nasopharynx; obstructive sleep apnea; oropharynx; standing position; vertebral column.

Accepted for publication: 26 September 2017

To cite this article:

Sonnesen L, Petersson A, Berg S, Svanholt P.

Pharyngeal Airway Dimensions and Head Posture in Obstructive Sleep Apnea Patients with and without Morphological Deviations in the Upper Cervical Spine

J Oral Maxillofac Res 2017;8(3):e4

URL: http://www.ejomr.org/JOMR/archives/2017/3/e4/v8n3e4.pdf

doi: $10.5037 /$ jomr.2017.8304 


\section{INTRODUCTION}

Obstructive sleep apnea (OSA) is by far the most common sleep-related breathing disorder, affecting $2-4 \%$ of the adult population, particularly males aged 60 years and older where the prevalence is 30 - $60 \%[1,2]$. OSA is defined as cessation of airflow with persistent respiratory effort, due to repeated anatomical obstruction or partial collapse of the oropharyngeal region, involving the soft palate, dorsum of the tongue and the posterior pharyngeal wall $[\underline{1}, \underline{3}]$. OSA is multifactorial with age, gender and body mass index (BMI) as predisposing factors $[\underline{1}, \underline{3}]$. Authors agree that there are craniofacial morphological and postural characteristics in OSA patients such as reduced posterior airway space, abnormally long soft palate, low position of the hyoid bone and an extended head posture $[\underline{4}, \underline{5}]$.

The upper airway is normally maintained by the bony and cartilaginous structures surrounding the naso- and oropharynx. Located posterior to the pharynx, the cervical spine is composed of seven vertebrae that provide full range of motion to the neck through articulations with the occiput and between the vertebrae. Some studies have been performed on the relationship between the cervical spine and OSA. Pathological conditions as osteoarthritis of the cervical spine [6-8], cervical osteophytes [9-11] and osteochondromas $[\underline{12}, \underline{13}]$ have been reported in relation to OSA patients. Recently, the morphology of the upper cervical spine in patients with OSA has been described on two-dimensional lateral cephalograms $[14,15]$ and three-dimensional cone-beam computed tomography (CBCT) [16]. The prevalence of morphological deviations in the upper spine range between 32 and $46 \%$ and the deviations occurred significantly more often in OSA patients than in subjects with neutral occlusion and normal craniofacial morphology [14-16]. In addition, associations between OSA patients with upper spine morphological deviations and mandibular advancement device (MAD) treatment outcome have been reported [17].

Studies have also shown an association between upper cervical spine morphology and head posture evaluated on lateral cephalograms in healthy subjects or subjects with malocclusion [18-21]. Furthermore, associations between head posture and pharyngeal airway dimensions have been documented on lateral cephalograms in adults $[\underline{5}, 22-24]$. According to a recent systematic review, there may be a lack of evidence on the effect of head posture on the upper airway dimensions in three-dimensional imaging due to lack of standardized method of the head and tongue position during image acquisition [25]. Furthermore, the relationship between morphological deviations in the upper spine and pharyngeal airway dimensions in OSA patients has not previously been reported.

Due to the cervical spine's and head posture's close associations with the pharyngeal airway it seems clinically relevant to focus on the relationship between the upper cervical spine and sleep apnea on three-dimensional imaging of OSA patients in a standardized head position.

The aims of the present study were to analyse: 1) differences in pharyngeal airway dimensions between OSA patients with and without upper spine morphological deviations, 2) differences in head posture between OSA patients with and without upper spine morphological deviations and 3) associations between pharyngeal airway dimensions and head posture in the total sample of CBCTs taken in a standardized head position.

\section{MATERIAL AND METHODS Subjects}

The first 53 patients with apnoea-hypopnoea index $(\mathrm{AHI})>5$ were enrolled as a part of a longitudinal sleep apnea study at the Orthodontics Section, Department of Odontology, University of Copenhagen, Denmark, in the period from January 2012 to May 2013 form part of the present study. The patients were diagnosed with OSA by sleep studies, using overnight polygraphy (Embletta Portable Diagnostic System, Iceland). Definition of AHI: apnea as cessation of airflow more than 10 seconds, hypopnea as reduction in airflow of at least $30 \%$ with an associated desaturation of $4 \%$. The sample was divided according to a visual assessment of morphological deviations in the upper cervical spine on three-dimensional images using the NewTom NNT software (QR srl, Verona, Italy) and analysed according to Sandham [26] as fusion of the vertebra units and posterior arch deficiencies. The findings were categorized as morphological deviations of the upper cervical spine, yes/no and have previous been described in details [16]. A total of $32.1 \%$ of the OSA patients had morphological deviations in the upper spine. Accordingly two groups were defined: 17 OSA patients, 7 women and 10 men aged between 27 and 76 years (mean 58.1 [SD 13.1] years) with morphological deviations in the upper spine and 36 OSA patients, 10 women and 26 men aged between 26 and 72 years (mean 49 [SD 10.1] years) without morphological deviations in the upper spine. 
In OSA patients with morphological deviations in the upper spine AHI ranged between 9 and 35 (mean 20.41 [SD 8.49]) and in OSA patients without morphological deviations in the upper spine AHI ranges between 7 and 57 (mean 20.17 [SD 11.76]). No statistical gender or AHI differences were found between the groups, but the patients with morphological deviations in the upper spine were older than the patients without spine deviations $(\mathrm{P}<0.05)$. All participants had read and signed the informed consent form. The study had been approved by the Ethical Committee for Copenhagen, Denmark (Ref. No. H-3-2011-086) and the Danish Data Protection Agency (J. No. 2012-54-0041).

\section{Methods}

The CBCTs were taken in a NewTom VGI unit (QR srl, Verona, Italy) of standing OSA patients with the teeth in occlusion and in the standardized head posture in the self-balance position as described by Siersbaek-Nielsen and Solow [27]. The settings were as followed: standard scan mode with an imaging volume of $15 \times 15 \mathrm{~cm}$, scan time 18 seconds and axial thickness of $0.3 \mathrm{~mm}$. The pharyngeal airway distances and cross-sectional areas were analysed using the ITK-Snap software [28] and the pharyngeal airway volumes were analysed by Romexis software (Planmeca Company, Helsinki, Finland). Twodimensional images were generated with the Romexis software in the mid sagittal plane and the head posture was analysed using View Box $3^{\circledR}$

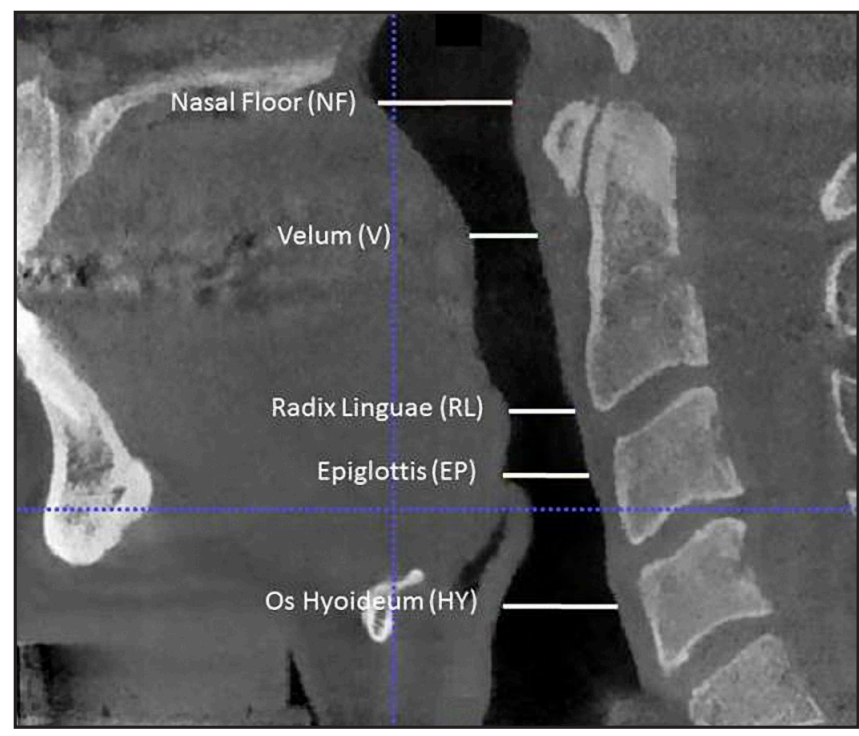

Figure 1. Pharyngeal reference levels illustrated in the mid sagittal view. $\mathrm{NF}=$ nasal floor, through the most posterior and inferior point of the cavum nasi; $\mathrm{V}=$ velum, the shortest antero-posterior distance behind velum palate; $\mathrm{RL}=$ radix linguae, the narrowest point behind radix linguae; $\mathrm{EP}=$ epiglottis, the level through the top of epiglottis; $\mathrm{HY}=$ hyoid bone, the level where the vocal chord is visible.
(Demetrios Halaznetis, Athens, Greece).

\section{Pharyngeal airway dimensions}

The sagittal and transversal linear distances were measured at five horizontal levels: the nasal floor (NF), velum (V), radix linguae (RL), epiglottis (EP) and hyoid bone (HY) (Figure 1, Table 1) according to the levels defined in the two-dimensional sagittal plane by Solow et al. [5] and in three-dimensional according to Sears et al. [29]. Furthermore, as the shape of the pharynx at the $\mathrm{V}$ level was kidney-shaped, the sagittal distances were also measured at the largest distance in the right and left sides (Figure 2, Table 1).

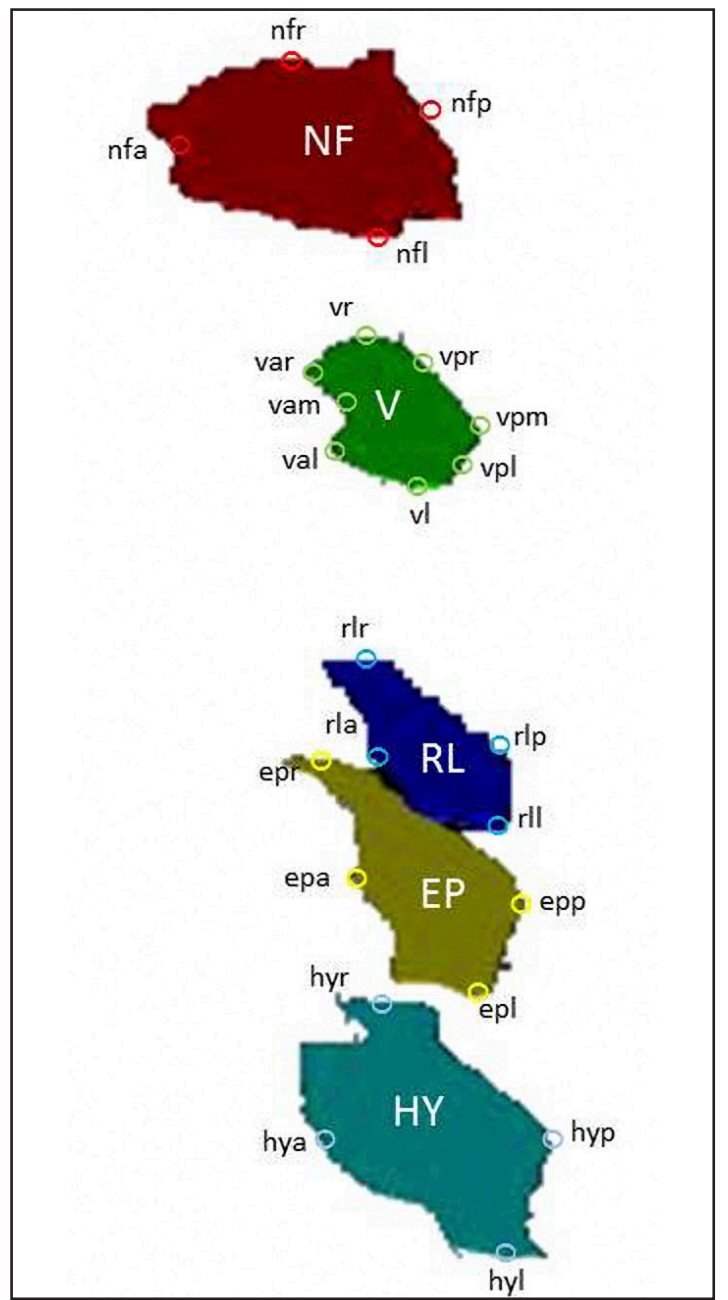

Figure 2. Pharyngeal reference points. $\mathrm{NF}=$ nasal floor level: most anterior (nfa) and posterior (nfp) point in the sagittal plane, the most right (nfr) and left (nfl) point. $\mathrm{V}=$ velum level: the most anterior (vam) and posterior (vmp) point in the sagittal plane, the most anterior (var) and posterior point (vpr) in the right part, the most anterior (val) and posterior point (vpl) in the left part. RL = radix linguae level: most anterior (rla) and posterior point (rlp) in the sagittal plane, the most right (rlr) and left (rll) point. $\mathrm{EP}=$ epiglottis level: most anterior (epa) and posterior point (epp) in the sagittal plane, the most right (epr) and left (epl) point. $\mathrm{HY}=$ hyoid bone level: most anterior (hya) and posterior (hyp) point in the sagittal plane, the most right (hyr) and left (hyl) point. 
Table 1. Postural variables and pharyngeal dimensions in obstructive sleep apnea subjects with and without upper spine deviations

\begin{tabular}{|c|c|c|c|c|c|c|c|}
\hline & \multicolumn{3}{|c|}{ With spine deviations } & \multicolumn{3}{|c|}{ Without spine deviations } & \multirow{2}{*}{$\mathbf{P}$} \\
\hline & $\mathbf{N}$ & Mean & SD & $\mathbf{N}$ & Mean & SD & \\
\hline \multicolumn{8}{|c|}{ Head posture $\left({ }^{\circ}\right)$} \\
\hline \multicolumn{8}{|l|}{ Craniovertical angles } \\
\hline FH/VER & 15 & 95.31 & 5.36 & 31 & 92.97 & 4.91 & NS \\
\hline NL/VER & 15 & 93.02 & 6,93 & 30 & 89.64 & 8.59 & NS \\
\hline \multicolumn{8}{|l|}{ Craniocervical angles } \\
\hline $\mathrm{NL} / \mathrm{CVT}$ & 15 & 108.17 & 9.43 & 30 & 106.52 & 9.52 & NS \\
\hline $\mathrm{NL} / \mathrm{OPT}$ & 15 & 92.15 & 9.8 & 30 & 95.67 & 9.19 & NS \\
\hline $\mathrm{FH} / \mathrm{CVT}$ & 16 & 103.69 & 7.22 & 31 & 104.96 & 8.06 & NS \\
\hline FH/OPT & 15 & 94.42 & 8.91 & 31 & 99.02 & 8.06 & NS \\
\hline \multicolumn{8}{|l|}{ Cervicohorizontal angles } \\
\hline CVT/HOR & 16 & 74.71 & 6.22 & 36 & 73.07 & 7.92 & NS \\
\hline OPT/HOR & 16 & 90.45 & 7.42 & 36 & 83.85 & 7.22 & $\mathrm{~b}, \mathrm{c}$ \\
\hline \multicolumn{8}{|l|}{ Cervical curvature } \\
\hline $\mathrm{OPT} / \mathrm{CVT}$ & 17 & 15.89 & 8.12 & 36 & 10.79 & 4.3 & a \\
\hline \multicolumn{8}{|c|}{ Pharyngeal dimensions $\left(\mathrm{mm} / \mathrm{mm}^{2} / \mathrm{mm}^{3}\right)$} \\
\hline \multicolumn{8}{|l|}{ Nasal floor level } \\
\hline Transversal distance & 17 & 28.31 & 4.39 & 36 & 27.84 & 5.47 & NS \\
\hline Sagittal distance & 17 & 21.56 & 4.06 & 36 & 20.33 & 3.4 & NS \\
\hline Area & 17 & 533.33 & 154.53 & 36 & 469.2 & 121.68 & NS \\
\hline \multicolumn{8}{|l|}{ Velum level } \\
\hline Transversal distance & 17 & 23.15 & 6.86 & 36 & 24.28 & 6.82 & NS \\
\hline Mean sagittal distance & 17 & 6.21 & 2.15 & 36 & 6.72 & 2.32 & NS \\
\hline Area & 17 & 136.93 & 77.86 & 36 & 155.81 & 95 & NS \\
\hline \multicolumn{8}{|l|}{ Radix lingual level } \\
\hline Transversal distance & 17 & 31.59 & 14.16 & 36 & 31.28 & 6.53 & NS \\
\hline Sagittal distance & 17 & 10.75 & 3.96 & 36 & 10.92 & 4 & NS \\
\hline Area & 17 & 264.49 & 152.63 & 36 & 257.62 & 103.47 & NS \\
\hline \multicolumn{8}{|l|}{ Epiglottis level } \\
\hline Transversal distance & 17 & 30.62 & 6 & 36 & 33.03 & 5.44 & NS \\
\hline Sagittal distance & 17 & 13.13 & 4.7 & 36 & 13.07 & 3.83 & NS \\
\hline Area & 17 & 314.46 & 158.13 & 36 & 311.15 & 117.65 & NS \\
\hline \multicolumn{8}{|l|}{ Hyoid bone level } \\
\hline Transversal distance & 17 & 38.01 & 3.75 & 36 & 38.95 & 4.19 & NS \\
\hline Sagittal distance & 17 & 16.73 & 3.84 & 36 & 17 & 3.56 & NS \\
\hline Area & 17 & 418.5 & 119.32 & 36 & 440.38 & 114.2 & NS \\
\hline \multicolumn{8}{|c|}{ Pharyngeal high and volume } \\
\hline Pharynx total high & 17 & 54.49 & 6.7 & 36 & 56.23 & 7.83 & NS \\
\hline Total pharyngeal volume & 17 & 12928 & 6274 & 36 & 12666 & 6381 & NS \\
\hline Velopharyngeal volume & 17 & 6799 & 3589 & 36 & 6729 & 5085 & NS \\
\hline Oropharyngeal volume & 17 & 6129 & 3952 & 36 & 5937 & 3436 & NS \\
\hline
\end{tabular}

${ }^{\mathrm{a} P}<0.05$; ${ }^{\mathrm{b}} \mathrm{P}<0.01$; ${ }^{\mathrm{c} g e n d e r}$ effect $(\mathrm{P}<0.05)$. Multiple linear regression analysis.

$\mathrm{N}=$ number of patients; $\mathrm{SD}=$ standard deviation; NS = not significant; FH/VER = the angle between Frankfort horizontal and true vertical line; NL/VER = the angle between nasal line and true vertical line; NL/CVT $=$ the angle between nasal line and cervical vertebra tangent line; $\mathrm{NL} / \mathrm{OPT}=$ the angle between nasal line and odontoid process tangent line; $\mathrm{FH} / \mathrm{CVT}=$ the angle between Frankfort horizontal and cervical vertebra tangent line; FH/OPT = the angle between Frankfort horizontal and odontoid process tangent line; $\mathrm{CVT} / \mathrm{HOR}=$ the angle between cervical vertebra tangent and true horizontal line; OPT/HOR = the angle between odontoid process tangent and true horizontal line; $\mathrm{OPT} / \mathrm{CVT}=$ the angle between odontoid process tangent and cervical vertebra tangent line. 
The cross-sectional areas were assessed by marking the edge of the pharynx aperture and the area was then calculated by the software within the defined points and margins (Figure 2, Table 1).

The pharyngeal volume was assessed as described by Anandarajah et al. [30]. The volumes were defined according to Sears et al. [29] as the total pharyngeal volume between NF and $\mathrm{EP}$, the oropharyngeal volume between $\mathrm{V}$ and $\mathrm{EP}$ and the nasopharyngeal volume as the difference between the total volume and the oropharyngeal volume (Figure 3, Table 1). The airway volumes were then automatically calculated by the software within the defined margins (Table 1).

\section{Head posture}

Nine variables representing the craniovertical, craniocervical and cervicohorizontal postural relationships and the curvature of the upper cervical spine was defined according to Solow and Tallgren [31]. As the cranial base and thereby the nasion-sella line (NSL) was not visible on some of the CBCTs the Frankfort horizontal line was used instead in all OSA patients. The reference points and lines are illustrated in Figure 4 and the mean values are shown in Table 1.

\section{Reliability}

The reliability of the variables describing the pharyngeal airway dimensions and head posture were assessed by re-measuring 25 lateral CBCTs selected at random from the previously evaluated CBCTs. The CBCTs were marked and measured again, and paired t-test found no significant differences between the two sets of recordings. The method errors calculated by Dahlberg's formula [32] for the head posture ranged from 0.04 to 2.5 degrees and the Houston reliability coefficient [33] from 0.7 to 1 . The method errors for the distances of the pharyngeal airway ranged from 0.08 to $3.35 \mathrm{~mm}$ and the Houston reliability coefficient from 0.73 to 1 . The method errors for the cross-sectional areas of the pharyngeal airway ranged from 4.6 to $52.4 \mathrm{~mm}^{2}$ and the Houston reliability coefficient from 0.79 to 1 . The method errors for the volumes of the pharyngeal airway ranged from 549.1 to $1270.8 \mathrm{~mm}^{3}$ and the Houston reliability coefficient from 0.92 to 0.99 .

\section{Statistical analysis}

The normality of distributions regarding the pharyngeal airway dimensions and the head posture was assessed by parameters of skewness and kurtosis and by Shapiro-Wilks W-test. Cervical lordosis (OPT/ CVT), velum area and the pharyngeal airway volume were not normally distributed. Once the variables were transformed logarithmically they became normally distributed.

Differences in means of pharyngeal airway dimensions and head posture between the two groups were assessed by unpaired t-test and adjusted for age and gender by multiple linear regression analyses. Associations between head posture and airway dimensions adjusted for age and gender were assessed by multiple linear regression analysis. Parametric data were expressed as mean and standard deviation (M [SD]).

The results from the tests were considered significant at P-values below 0.05 . The statistical analyses were performed using SPSS 20.00 (Inc., Chicago, Illinois, USA).

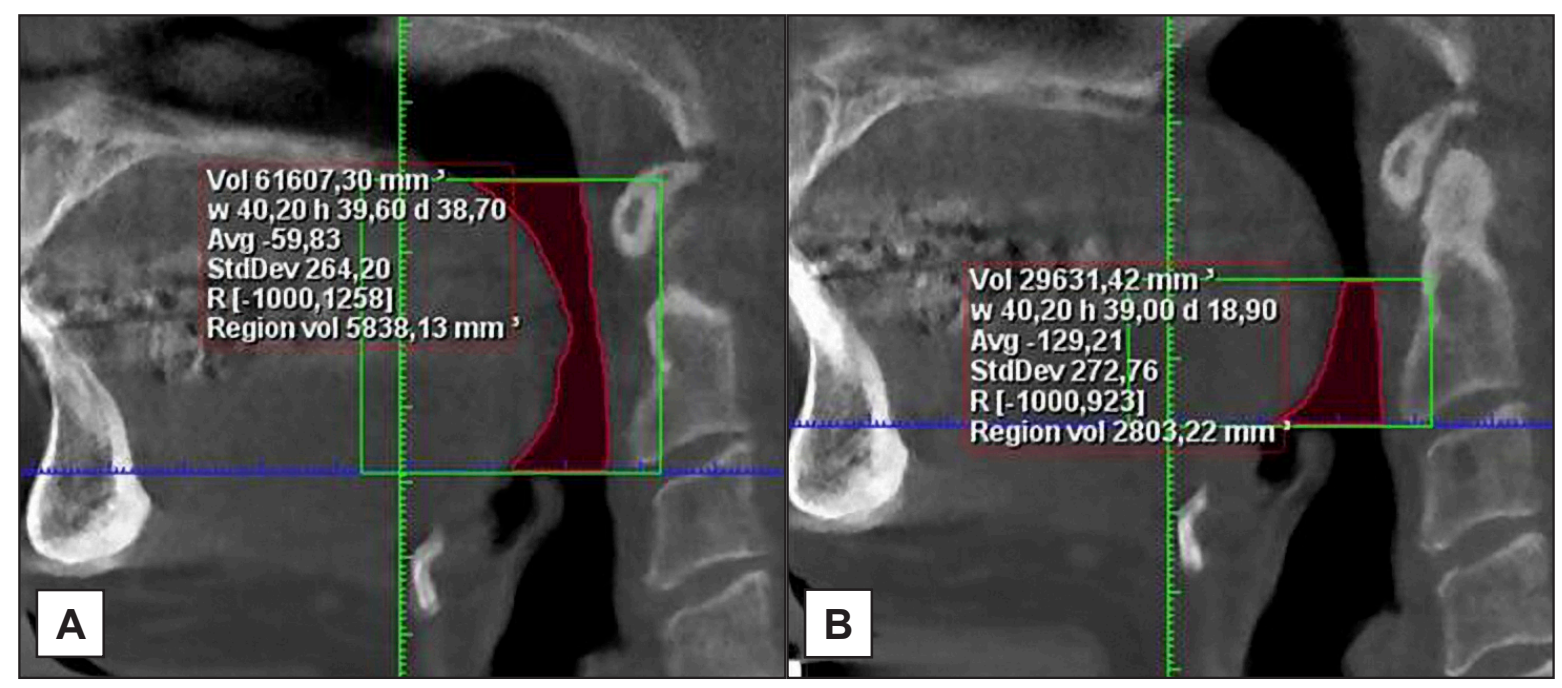

Figure 3. Illustration of pharyngeal volumes in the mid sagittal view. A = total pharyngeal volume between nasal floor plane and epiglottis plane; $\mathrm{B}=$ oropharyngeal volume between velum plane and epiglottis plane. 


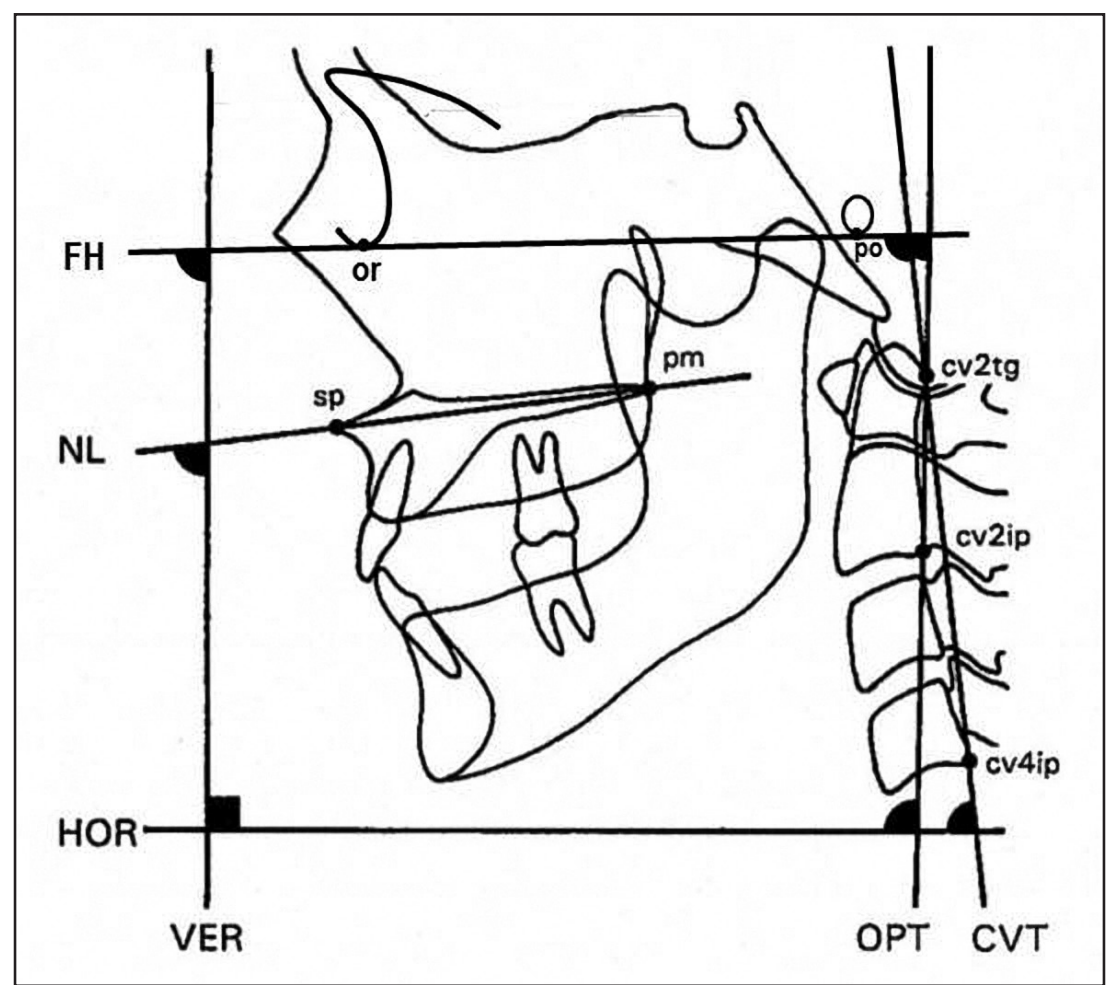

Figure 4. Reference points and lines describing the head posture on two-dimensional generated lateral cephalogram [31].

$\mathrm{FH}=$ Frankfurter horizontal through or and po; or = orbitale, the most inferior point of foramen orbitale; po = porion, the most inferior point of apertura acusticus.

$\mathrm{NL}=$ nasal line through sp and $\mathrm{pm} ; \mathrm{sp}=$ spinal point, the apex of in the anterior nasal spine; $\mathrm{pm}=$ pterygomaxillare, the intersection between the nasal floor and the posterior contour of the maxilla.

$\mathrm{OPT}=$ odontoid process tangent through cv2ip and cv2tg; $\mathrm{cv} 2 \mathrm{ip}=$ the most posteroinferior point on the corpus of $\mathrm{C} 2 ; \mathrm{cv} 2 \mathrm{tg}=\operatorname{the} \operatorname{tangent}$ point on the dorsal contour of the odontoid process of $\mathrm{C} 2$ to a line from cv2ip.

$\mathrm{CVT}=$ cervical vertebra tangent through cv4ip and cv2tg; cv4ip = the most posteroinferior point on the corpus of C4.

$\mathrm{VER}=$ true vertical line $\mathrm{HOR}=$ true horizontal line. Postural angles are indicated in black.

Table 2. Significant associations between pharyngeal airway dimensions and head posture adjusted for age and gender in the total group $(\mathrm{n}=53)$

\begin{tabular}{c|c|c|c|c|c|c|c|c}
\hline Level & \multicolumn{3}{|c|}{ Nasal floor level } & \multicolumn{2}{c|}{ Epiglottis level } & \multicolumn{3}{c}{ Hyoid bone level } \\
\hline Variable & $\begin{array}{c}\text { Transversal } \\
\text { distance }\end{array}$ & $\begin{array}{c}\text { Sagittal } \\
\text { distance }\end{array}$ & Area & $\begin{array}{c}\text { Transversal } \\
\text { distance }\end{array}$ & $\begin{array}{c}\text { Sagittal } \\
\text { distance }\end{array}$ & $\begin{array}{c}\text { Transversal } \\
\text { distance }\end{array}$ & $\begin{array}{c}\text { Sagittal } \\
\text { distance }\end{array}$ & Area \\
\hline
\end{tabular}

\begin{tabular}{|c|c|c|c|c|c|c|c|c|}
\hline \multicolumn{9}{|c|}{ Craniovertical angles $\left({ }^{\circ}\right)$} \\
\hline FH/VER & $0.36^{\mathrm{a}}$ & $0.39^{\mathrm{a}}$ & $0.33^{\mathrm{a}}$ & - & - & - & - & - \\
\hline NL/VER & - & - & - & - & - & - & - & - \\
\hline \multicolumn{9}{|c|}{ Craniocervical angles $\left({ }^{\circ}\right)$} \\
\hline $\mathrm{NL} / \mathrm{CVT}$ & - & - & - & - & - & $0.31^{\mathrm{a}}$ & $0.42^{\mathrm{b}}$ & $0.45^{\mathrm{b}}$ \\
\hline NL/OPT & - & - & - & - & - & - & $0.42^{\mathrm{b}}$ & $0.31^{\mathrm{a}}$ \\
\hline $\mathrm{FH} / \mathrm{CVT}$ & - & - & - & $0.32^{\mathrm{a}}$ & $0.32^{\mathrm{a}}$ & $0.4^{\mathrm{b}}$ & $0.49^{\mathrm{c}}$ & $0.5^{\mathrm{c}}$ \\
\hline FH/OPT & - & - & - & $0.3^{\mathrm{a}}$ & $0.3^{\mathrm{a}}$ & $0.32^{\mathrm{a}}$ & $0.5^{\mathrm{c}}$ & $0.46^{\mathrm{b}}$ \\
\hline \multicolumn{9}{|c|}{ Cervicohorizontal angles $\left({ }^{\circ}\right)$} \\
\hline $\mathrm{CVT} / \mathrm{HOR}$ & - & - & - & - & - & $-0.43^{b}$ & $-0.46^{\mathrm{b}}$ & $-0.57^{\mathrm{c}}$ \\
\hline OPT/HOR & - & - & - & - & - & - & $-0.53^{\mathrm{b}, \mathrm{d}}$ & $-0.51^{b, d}$ \\
\hline
\end{tabular}

a $\mathrm{P}<0.05$; ${ }^{\mathrm{b}} \mathrm{P}<0.01 ;{ }^{\mathrm{c}} \mathrm{P}<0.001$. ${ }^{\mathrm{d}}$ Age effect $(\mathrm{P}<0.05)$. Multiple linear regression analysis.

$\mathrm{FH} / \mathrm{VER}=$ the angle between Frankfort horizontal and true vertical line; NL/VER $=$ the angle between nasal line and true vertical line; $\mathrm{NL} / \mathrm{CVT}=$ the angle between nasal line and cervical vertebra tangent line; NL/OPT $=$ the angle between nasal line and odontoid process tangent line; FH/CVT = the angle between Frankfort horizontal and cervical vertebra tangent line; FH/OPT = the angle between Frankfort horizontal and odontoid process tangent line; $\mathrm{CVT} / \mathrm{HOR}=$ the angle between cervical vertebra tangent and true horizontal line; $\mathrm{OPT} / \mathrm{HOR}=$ the angle between odontoid process tangent and true horizontal line; OPT/CVT $=$ the angle between odontoid process tangent and cervical vertebra tangent line. 


\section{RESULTS}

\section{Differences between the groups}

The cervicohorizontal angle (OPT/HOR) and OPT/ CVT was significantly larger in OSA patients with morphological deviations in the upper spine compared to OSA patients without upper spine deviations ( $\mathrm{P}$ $<0.01, \mathrm{P}<0.05$, respectively; Table 1), meaning a more backward and curved neck posture in OSA patients with upper spine morphological deviations compared to OSA patients without spine deviations. No significant differences were found in airway dimensions between patients with and without upper spine morphological deviations (Table 1).

\section{Associations}

When associations between head posture and pharyngeal airway distances and cross-sectional areas were adjusted for age and gender a clear pattern was found between head posture and the pharyngeal airway distances and cross-sectional area at the HY level (Table 2). Thus, the craniocervical posture (FH/ OPT, FH/CVT, NL/OPT, NL/CVT) was significantly positively associated with airway distances and crosssectional area at the HY level $(\mathrm{P}<0.05, \mathrm{P}<0.01$, $\mathrm{P}<0.001$; Table 2) and the cervicohorizontal posture (OPT/HOR, CVT/HOR) was significantly negatively associated with airway distances and cross-sectional area at the HY level $(\mathrm{P}<0.01, \mathrm{P}<0.001$; Table 2$)$ meaning larger airway distances and cross-sectional area at the HY level with an extended and forward head posture. Furthermore, the craniocervical posture (FH/OPT, FH/CVT) was significantly positively associated with the pharyngeal airway distances at the EP $(\mathrm{P}<0.05$; Table 2$)$, and the craniovertical posture (FH/VER) was significantly positively associated with the pharyngeal airway distances and cross-sectional area at the NF level $(\mathrm{P}<0.05$; Table 2). No significant associations were found between head posture and pharyngeal airway volume (Table 2).

\section{DISCUSSION}

The aim of the present study was to analyse differences in pharyngeal airway dimensions and head posture between OSA patients with and without morphological deviations in the upper cervical spine and to study associations between pharyngeal airway dimensions and head posture on three-dimensional CBCT taken in a standardized head position. To our knowledge differences in pharyngeal airway dimensions and head posture between OSA patients with and without morphological deviations in the upper spine have not previously been reported in the literature. Furthermore it is still uncertain how the head posture affects the upper airway dimensions analysed on three-dimensional CBCT taken in a standardized head position [25].

\section{Differences between groups}

In the present study, OSA patients with morphological deviations in the upper spine had a significantly more backward and curved neck posture compared to OSA patients without spine deviations. The findings were in agreement with previous studies where an association was found between morphological deviations in the upper spine and posture of the head and neck in healthy adults [18] and in children with class II malocclusion [19].

A direct relationship between morphological deviations in the upper spine and pharyngeal airway dimensions could not be verified in the present study. Previous studies have shown that morphological deviations in the upper spine occurred significantly more often in OSA patients compared to healthy controls $[14,15]$ and that the craniofacial profile of OSA patients with block fusions in the upper cervical spine and fusion of two vertebrae differed significantly from the craniofacial profile of other OSA patients [15]. Therefore the morphological deviations in the upper spine contribute to phenotypic differentiations between types of OSA and thereby to the diagnosis and subdivision of patients with OSA $[\underline{14}, \underline{15}]$. Furthermore, OSA patients with morphological deviations in the upper spine show a worse response to MAD treatment compared to OSA patients without morphological deviations in the upper spine [17]. The findings indicate that the aetiology in OSA patients with morphological deviations in the upper spine is characterised by other factors or combinations of different factors than in OSA patients without upper spine morphological deviations $[14, \underline{15}, 17]$.

Specific cervical spine pathologies, such as osteophytes, osteoarthritis and osteochondromas are conditions associated with OSA that may be due to a direct relationship to the pharyngeal dimensions resulting in a decrease in the pharyngeal airway dimensions [6-13]. Often these pathological conditions are parts of general syndromes that cause OSA [34] and thereby make it difficult to distinguish if it is the general syndrome or the cervical spine pathology that results in a decreased airway dimension. The association between OSA 
and morphological deviations in the upper cervical spine found in previous studies [14-16] could not be explained by a direct relationship to the pharyngeal airway dimensions. No significant differences in the pharyngeal airway dimensions between patients with and without upper spine morphological deviations were found in the present study. Results from previous study [17] indicate that OSA patients with upper spine morphological deviations may respond poorly to MAD treatment. The results from the present study showed no statistically significant differences in upper airway dimensions between OSA patients with and without upper spine morphological deviations. Therefore it may be suggested the OSA patients with upper spine morphological deviations should be treated with constant positive airway pressure and OSA patients without upper spine morphological deviations should be treated with MAD. This recommendation should be investigated with future research.

\section{Associations}

When the CBCT was taken in the standardized head posture a clear pattern was found between head posture and the pharyngeal airway distances and cross-sectional area at the HY level: an extended and forward head posture was associated with larger airway distances and cross-sectional area at the HY level. These findings were in agreement with a previous study using two-dimensional lateral cephalograms of OSA patients taken in the standardized head position which showed that an extended and forward head posture was associated with the anterior-posterior airway distances especially in the lower part of the pharyngeal airway [5]. Since the previous study used a two-dimensional method the pharyngeal airway volume was not assessed. Another previous study using three-dimensional magnetic resonance imaging of children with sleepdisordered breathing, found an association between various head positions and the oropharyngeal volume [35]. Interestingly, the present study of CBCTs in the standardized head position did not show an association between head posture and pharyngeal airway volumes, only pharyngeal airway distances and cross-sectional area. This is new and important knowledge as the previous described compensatory physiological postural mechanism that serves to maintain airway adequacy in OSA patients [5] may be due to a stretch of the pharyngeal airway at the HY level and not due to an increased airway volume. Pharyngeal airway patency depends on the relative influence of pharyngeal airway dimensions, pharyngeal airway compliance and the negative intraluminal pressure during inspiration $[\underline{36}, \underline{37}]$. Therefore, the stretch of the pharyngeal airway with an extended and forward head posture found in the present study may decrease the risk of airway collapsibility due to changes in pharyngeal airway dimensions and interluminal pressure during inspiration locally at the HY level and not by an increased airway volume as previously suggested $[\underline{5}, \underline{35}]$.

\section{CONCLUSIONS}

Head posture was significantly different between patients with and without upper spine morphological deviations. No significant differences in airway dimensions between patients with and without upper spine morphological deviations were found. Head posture was associated with pharyngeal airway distances and cross-sectional areas but not with pharyngeal airway volume. These results may contribute to help differentiate obstructive sleep apnea patients and thereby may prove valuable in future diagnosis and treatment planning of obstructive sleep apnea patients.

\section{ACKNOWLEDGMENTS AND DISCLOSURE STATEMENTS}

The authors report no conflicts of interest related to this study. The authors would like to thank Eva Marie Reinwald (Department of Odontology, University of Copenhagen) for manuscript preparation. The study is funded by strategic funding from the Department of Odontology, Faculty of Health and Medical Sciences, University of Copenhagen, Denmark (Strategimidler OI 2011) and the Danish Dental Association Foundation (28-05-2014, KOF).

\section{REFERENCES}

1. Prisant LM, Dillard TA, Blanchard AR. Obstructive sleep apnea syndrome. J Clin Hypertens (Greenwich) 2006 Oct; 8(10): 746-50. [doi: 10.1111/j.1524-6175.2006.888139.x]

2. Wolkove N, Elkholy O, Baltzan M, Palayew M. Sleep and aging: 1. Sleep disorders commonly found in older people. CMAJ. 2007 Apr 24;176(9):1299-304. [Medline: 17452665] [PMC free article: 1852874] [doi: 10.1503/cmaj.060792] 
3. Guilleminault C, Tilkian A, Dement WC. The sleep apnea syndromes. Annu Rev Med. 1976;27:465-84. [doi: 10.1146/annurev.me.27.020176.002341]

4. Neelapu BC, Kharbanda OP, Sardana HK, Balachandran R, Sardana V, Kapoor P, Gupta A, Vasamsetti S. Craniofacial and upper airway morphology in adult obstructive sleep apnea patients: A systematic review and meta-analysis of cephalometric studies. Sleep Med Rev. 2017 Feb;31:79-90. [Medline: 27039222] [doi: 10.1016/j.smrv.2016.01.007]

5. Solow B, Skov S, Ovesen J, Norup PW, Wildschiødtz G. Airway dimensions and head posture in obstructive sleep apnoea. Eur J Orthod. 1996 Dec;18(6):571-9. [Medline: 9009421] [doi: 10.1093/ejo/18.6.571]

6. Shoda N, Seichi A, Takeshita K, Chikuda H, Ono T, Oka H, Kawaguchi H, Nakamura K. Sleep apnea in rheumatoid arthritis patients with occipitocervical lesions: the prevalence and associated radiographic features. Eur Spine J. 2009 Jun;18(6):905-10. [Medline: 19365641] [PMC free article: 2899654] [doi: 10.1007/s00586-009-0975-Z]

7. Nguyen HV, Ludwig SC, Silber J, Gelb DE, Anderson PA, Frank L, Vaccaro AR. Rheumatoid arthritis of the cervical spine. Spine J. 2004 May-Jun;4(3):329-34. [Medline: 15125859] [doi: 10.1016/j.spinee.2003.10.006]

8. Drossaers-Bakker KW, Hamburger HL, Bongartz EB, Dijkmans BA, Van Soesbergen RM. Sleep apnoea caused byrheumatoidarthritis. BrJRheumatol.1998Aug;37(8):889-94. [Medline:9734681] [doi:10.1093/rheumatology/37.8.889]

9. Eyigor H, Selcuk OT, Osma U, Koca R, Yilmaz MD. Cervical osteophytes: a rare cause of obstructive sleep apnea. J Craniofac Surg. 2012 Sep;23(5):e444-6. [Medline: 22976699] [doi: 10.1097/SCS.0b013e318260e9ea]

10. Ando E, Ogawa T, Shigeta Y, Hirai S, Ikawa T, Ishikawa C, Nejima J. A case of obstructive sleep apnoea with anterior cervical osteophytes. J Oral Rehabil. 2009 Oct;36(10):776-80. [Medline: 19702680] [doi: 10.1111/j.1365-2842.2009.01984.x]

11. Fuerderer S, Eysel-Gosepath K, Schröder U, Delank KS, Eysel P. Retro-pharyngeal obstruction in association with osteophytes of the cervical spine. J Bone Joint Surg Br. 2004 Aug;86(6):837-40. [Medline: 15330024] [doi: 10.1302/0301-620X.86B6.14933]

12. Wang V, Chou D. Anterior C1-2 osteochondroma presenting with dysphagia and sleep apnea. J Clin Neurosci. 2009 Apr;16(4):581-2. [Medline: 19195892] [doi: 10.1016/j.jocn.2008.05.024]

13. Yoshida T, Matsuda H, Horiuchi C, Taguchi T, Nagao J, Aota Y, Honda A, Tsukuda M. A case of osteochondroma of the atlas causing obstructive sleep apnea syndrome. Acta Otolaryngol. 2006 Apr;126(4):445-8. [Medline: 16608803] [doi: 10.1080/00016480500416793]

14. Sonnesen L, Petri N, Kjaer I, Svanholt P. Cervical column morphology in adult patients with obstructive sleep apnoea. Eur J Orthod. 2008 Oct;30(5):521-6. [Medline: 18647950] [doi: 10.1093/ejo/cjn028]

15. Svanholt P, Petri N, Wildschiødtz G, Sonnesen L, Kjaer I. Associations between craniofacial morphology, head posture, and cervical vertebral body fusions in men with sleep apnea. Am J Orthod Dentofacial Orthop. 2009 Jun;135(6):702.e1-9; discussion 702-3. [Medline: 19524827] [doi: 10.1016/j.ajodo.2009.02.011]

16. Sonnesen L, Jensen KE, Petersson AR, Petri N, Berg S, Svanholt P. Cervical vertebral column morphology in patients with obstructive sleep apnoea assessed using lateral cephalograms and cone beam CT. A comparative study. Dentomaxillofac Radiol. 2013;42(6):20130060. [Medline: 23503808] [PMC free article: 3667528] [doi: 10.1259/dmfr.20130060]

17. Svanholt P, Petri N, Wildschiødtz G, Sonnesen L. Influence of craniofacial and upper spine morphology on mandibular advancement device treatment outcome in patients with obstructive sleep apnoea: a pilot study. Eur J Orthod. 2015 Aug;37(4):391-7. doi: 10.1093/ejo/cju064. Epub 2014 Oct 28. [Medline: 25351571] [doi: 10.1093/ejo/cju064]

18. Sonnesen L, Pedersen CE, Kjaer I. Cervical column morphology related to head posture, cranial base angle, and condylar malformation. Eur J Orthod. 2007 Aug;29(4):398-403. [Medline: 17607022] [doi: 10.1093/ejo/cjm010]

19. Arntsen T, Sonnesen L. Cervical vertebral column morphology related to craniofacial morphology and head posture in preorthodontic children with Class II malocclusion and horizontal maxillary overjet. Am J Orthod Dentofacial Orthop. 2011 Jul;140(1):e1-7. [Medline: 21724066] [doi: 10.1016/j.ajodo.2010.10.021]

20. Kylämarkula S, Huggare J. Head posture and the morphology of the first cervical vertebra. Eur J Orthod. 1985 Aug;7(3):151-6. [Medline: 3862587] [doi: 10.1093/ejo/7.3.151]

21. Huggare J. Association between morphology of the first cervical vertebra, head posture, and craniofacial structures. Eur J Orthod. 1991 Dec;13(6):435-40. [Medline: 1817068] [doi: 10.1093/ejo/13.6.435]

22. Anegawa E, Tsuyama H, Kusukawa J. Lateral cephalometric analysis of the pharyngeal airway space affected by head posture. Int J Oral Maxillofac Surg. 2008 Sep;37(9):805-9. [Medline: 18468864] [doi: 10.1016/j.ijom.2008.03.006]

23. Muto T, Takeda S, Kanazawa M, Yamazaki A, Fujiwara Y, Mizoguchi I. The effect of head posture on the pharyngeal airway space (PAS). Int J Oral Maxillofac Surg. 2002 Dec;31(6):579-83. [Medline: 12521311] [doi: 10.1054/ijom.2002.0279]

24. Muto T, Yamazaki A, Takeda S, Kawakami J, Tsuji Y, Shibata T, Mizoguchi I. Relationship between the pharyngeal airway space and craniofacial morphology, taking into account head posture. Int J Oral Maxillofac Surg. 2006 Feb;35(2):132-6. [Medline: 15961280$]$ [doi: 10.1016/j.ijom.2005.04.022]

25. Gurani SF, Di Carlo G, Cattaneo PM, Thorn JJ, Pinholt EM. Effect of Head and Tongue Posture on the Pharyngeal Airway Dimensions and Morphology in Three-Dimensional Imaging: a Systematic Review. J Oral Maxillofac Res. 2016 Mar 31;7(1):e1. [Medline: 27099695] [PMC free article: 4837605] [doi: 10.5037/jomr.2016.7101]

26. Sandham A. Cervical vertebral anomalies in cleft lip and palate. Cleft Palate J. 1986 Jul;23(3):206-14. [Medline: 3524906 ]

27. Siersbaek-Nielsen S, Solow B. Intra- and interexaminer variability in head posture recorded by dental auxiliaries. Am J Orthod. 1982 Jul;82(1):50-7. [Medline: 6961777] [doi: 10.1016/0002-9416(82)90546-2] 
28. Yushkevich PA, Piven J, Hazlett HC, Smith RG, Ho S, Gee JC, Gerig G. User-guided 3D active contour segmentation of anatomical structures: significantly improved efficiency and reliability. Neuroimage. 2006 Jul 1;31(3):1116-28. [Medline: 16545965] [doi: 10.1016/j.neuroimage.2006.01.015]

29. Sears CR, Miller AJ, Chang MK, Huang JC, Lee JS. Comparison of pharyngeal airway changes on plain radiography and cone-beam computed tomography after orthognathic surgery. J Oral Maxillofac Surg. 2011 Nov;69(11):e385-94. [Medline: 21778015] [doi: 10.1016/j.joms.2011.03.015]

30. Anandarajah S, Abdalla Y, Dudhia R, Sonnesen L. Proposal of new upper airway margins in children assessed by CBCT. Dentomaxillofac Radiol. 2015;44(7):20140438. [Medline: 25806863] [doi: 10.1259/dmfr.20140438]

31. Solow B, Tallgren A. Natural head position in standing subjects. Acta Odontol Scand. 1971 Nov;29(5):591-607. [Medline: 5290983] [doi: $\underline{10.3109 / 00016357109026337]}$

32. Dahlberg G. Statistical Methods for Medical and Biological Students. Br Med J. 1940;2(4158):358-359. [PMC free article: 2179091]

33. Houston WJ. The analysis of errors in orthodontic measurements. Am J Orthod. 1983 May;83(5):382-90. [Medline: 6573846] [doi: 10.1016/0002-9416(83)90322-6]

34. Khan A, Than KD, Chen KS, Wang AC, La Marca F, Park P. Sleep apnea and cervical spine pathology. Eur Spine J. 2014 Mar;23(3):641-7. [Medline: 24121751] [PMC free article: 3940806] [doi: 10.1007/s00586-013-3046-4]

35. Pirilä-Parkkinen K, Pirttiniemi P, Pääkkö E, Tolonen U, Nieminen P, Löppönen H. Pharyngeal airway in children with sleep-disordered breathing in relation to head posture. Sleep Breath. 2012 Sep;16(3):737-46. [Medline: 21826530] [doi: $10.1007 / \mathrm{s} 11325-011-0569-y]$

36. Hudgel DW. Mechanisms of obstructive sleep apnea. Chest. 1992 Feb;101(2):541-9. [Medline: 1735286] [doi: $10.1378 /$ chest.101.2.541]

37. Mohsenin V. Effects of gender on upper airway collapsibility and severity of obstructive sleep apnea. Sleep Med. 2003 Nov;4(6):523-9. [Medline: 14607346] [doi: 10.1016/S1389-9457(03)00168-0]

\section{To cite this article:}

Sonnesen L, Petersson A, Berg S, Svanholt P.

Pharyngeal Airway Dimensions and Head Posture in Obstructive Sleep Apnea Patients with and without Morphological Deviations in the Upper Cervical Spine

J Oral Maxillofac Res 2017;8(3):e4

URL: http://www.ejomr.org/JOMR/archives/2017/3/e4/v8n3e4.pdf

doi: $10.5037 /$ jomr.2017.8304

Copyright (C) Sonnesen L, Petersson A, Berg S, Svanholt P. Published in the JOURNAL OF ORAL \& MAXILLOFACIAL RESEARCH (http://www.ejomr.org), 30 September 2017.

This is an open-access article, first published in the JOURNAL OF ORAL \& MAXILLOFACIAL RESEARCH, distributed under the terms of the Creative Commons Attribution-Noncommercial-No Derivative Works 3.0 Unported License, which permits unrestricted non-commercial use, distribution, and reproduction in any medium, provided the original work and is properly cited. The copyright, license information and link to the original publication on (http://www.ejomr.org) must be included. 